\title{
The Preparation of Mn-Fe/CNTs Catalyst at the Low-Temperature Selective Catalytic Reduction of $\mathrm{NO}$ with $\mathrm{NH}_{3}$
}

\author{
Bingnan Ren ${ }^{1,2}$ \\ ${ }^{1}$ The Zhaimingguo Academician Workstation, Sanya University, Sanya, China \\ ${ }^{2}$ School of Health Industry Management, Sanya University, Sanya, China \\ Email: renbingnan@126.com
}

How to cite this paper: Ren, B.N. (2018) The Preparation of Mn-Fe/CNTs Catalyst at the Low-Temperature Selective Catalytic Reduction of $\mathrm{NO}$ with $\mathrm{NH}_{3}$. Journal of Materials Science and Chemical Engineering, 6, 33-38.

https://doi.org/10.4236/msce.2018.612003

Received: December 15, 2018 Accepted: December 24, 2018 Published: December 31, 2018

\begin{abstract}
The metal oxide catalyst was prepared by loading $\mathrm{MnO}_{\mathrm{x}}$ and $\mathrm{FeO}_{\mathrm{x}}$ on carbon nano-tubes (CNTs) with impregnation method. Then the catalyst was characterized by BET and XPS, and the effect of adding $\mathrm{FeO}_{\mathrm{x}}$ on $\mathrm{M}_{\mathrm{n}} \mathrm{O}_{\mathrm{x}} / \mathrm{CNTs}$ catalyst at the low-temperature selective catalytic reduction of $\mathrm{NO}$ with $\mathrm{NH}_{3}$ was investigated. The results showed that the active components were loaded successfully and easily on the carriers by impregnation. The Mn-Fe/CNTs catalyst was chose $10 \% \mathrm{Fe}\left(\mathrm{NO}_{3}\right)_{3}$ solution to impregnate $\mathrm{Mn}-\mathrm{Fe} / \mathrm{CNT}$. The species of active components loaded on the catalyst were $\mathrm{Fe}_{2} \mathrm{O}_{3}$. The different concentration of impregnant solution played an important role for NO conversion in SCR with $\mathrm{NH}_{3}$. With the increase of the concentration of impregnant solution, the NO conversion of catalysts was increasing initially then decreasing.
\end{abstract}

\section{Keywords}

Carbon Nanotubes, Catalyst, Low-Temperature Selective Catalytic Reduction

\section{Introduction}

$\mathrm{NO}_{\mathrm{x}}$ pollutants can cause lung irritation and inhibit the body's ability to fight off diseases such as influenza and pneumonia. Long-term exposures to high concentrations of nitrogen dioxide can produce chronic damage to respiratory tract tissue that resembles the lung disease emphysema. The free radical then can react with organic compounds in the air to form nitrogenated organic compounds, some of which have been shown to be mutagenic and carcinogenic. Further high levels of $\mathrm{NO}_{\mathrm{x}}$ cause a variety of environmentally harmful effects 
such as acid rain and urban smog; they also contribute to the greenhouse effect. Therefore, it has become important to reduce the emission of nitrogen oxides from both stationary and mobile combustion technologies in order to keep the health of humans and protect environment.

Among various $\mathrm{NO}_{\mathrm{x}}$ emission control techniques, selective catalytic reduction (SCR) of $\mathrm{NO}$ with $\mathrm{NH}_{3}$ in the presence of excess oxygen has been proven to be the most effective which is widely used. It has been proved that the catalyst being prepared through supported metallic oxides are with good catalytic performance. Various metal oxide based catalysts have been shown to possess some potential for low temperature application, including $\mathrm{Mn}_{2} \mathrm{O}_{3}, \mathrm{CeO}_{2}, \mathrm{~V}_{2} \mathrm{O}_{5}$, etc.. As a novel carbon material, carbon nanotubes (CNTs) have attracted much attention due to their unique electric, mechanical and structural characteristics. It has been widely studied in fields of high strength carbon fiber materials [1], hydrogen storage materials [2] [3] [4], new catalytic materials [4] [5] [6] [7] [8], etc. Due to one-dimensional tubular structure of CNTs, catalytic materials with specific properties can be prepared in the cavity of tubular. So as a new catalytic material, CNTs have caused attention of many researchers [9] [10] [11].

Therefore, it can be an issue deserved intensive study to make use of CNTs to study the low-temperature selective catalytic reduction of $\mathrm{NO}$ with $\mathrm{NH}_{3}$. This research prepared $\mathrm{Mn} / \mathrm{CNTs}$ catalyst through supported manganese oxide, then adding iron oxide on the CNTs after purification. We have investigated the effect of adding $\mathrm{FeO}_{\mathrm{x}}$ on $\mathrm{MnO}_{\mathrm{x}} / \mathrm{CNT}$ s catalyst at the low-temperature selective catalytic reduction of $\mathrm{NO}$ with $\mathrm{NH}_{3}$.

\section{Experimental}

\subsection{Preparation of Catalyst}

Immerse right amount of $\mathrm{Mn} / \mathrm{CNTs}$ after purification in impregnating solution for 24 hours at room temperature, meanwhile, stir them with magnetic stirrer. Then, the end product of catalyst can be obtained after drying, cooling, grinding, and roasting the immersed catalyst.In the experiment, The ferric nitrate solution was choosed to prepare the two component catalyst.

\subsection{Catalysts Characterization}

We analyzed the catalysts characterizationby TEMand XPSof catalyst.Determine the TEM of catalyst by means of JEM-1200EX made in JEOL Ltd; XPS analysis can be carried out by making use of AXIS Ultra-type X-ray photoelectron spectroscopy made in England Kratos Company.

\subsection{Catalytic Activity Tests}

The catalytic activity tests were carried out in a fixed bed reactor made of stainless steel in the $150^{\circ} \mathrm{C} \sim 300^{\circ} \mathrm{C}$ range. The gas composition was $450 \mathrm{ppm}$ $\mathrm{NO}, 500 \mathrm{ppm} \mathrm{NH} \mathrm{NH}_{3}, 5 \% \mathrm{O}_{2}$ balanced by $\mathrm{N}_{2}$. The total flow rate was $500 \mathrm{ml} \cdot \mathrm{min}^{-1}$. The experimental apparatus of evaluation of the catalytic activity tests included 
sections of gas configuration, catalytic reaction and flue gas analysis, which was shown in Figure 1. NO concentrations in the inlet and outlet gases were measured by flue gas analyzer (KM940, Kane). The NO conversion was calculated from the NO concentration at the inlet and outlet of the reactor.

\section{Results and Discussions}

\subsection{Catalysts Characterization}

The surface morphology and microstructures of the catalysts can be observed directly by TEM. Figure 2 showed the TEM image of Mn/CNTs catalyst, 10\% $\mathrm{Mn}-\mathrm{Fe} / \mathrm{CNTs}$, 20\% Mn-Fe/CNTs.

The photographs of Mn/CNTs catalysts loaded with manganese oxides was in (1), (2) and (3) was photographs of the catalysts impregnated with different concentrations of ferric nitrate solution on Mn/CNTs catalysts. Metal oxide particles loaded on the CNTs was evenly on the surface of the carrier. Future researches should be worthy to be carried out to reveal the effect between the catalyst activity and the metal oxide particle dispersion. In addition, it can be seen that metal oxide particles supported on Mn/CNTs catalysts were relatively uniform and the agglomeration is smaller by adding ferric oxides, which improves the dispersion of the supported metal oxide particles.

Figure 3 illustrated the surface element concentration of Mn-Fe/CNTs catalyst by XPS spectra, in which (1), (2), (3), and (4) were separately Mn-Fe/CNTs catalyst spectra, $\mathrm{O}(1 \mathrm{~s})$ spectra, $\mathrm{Mn}(2 \mathrm{p})$ spectra, and Fe (2p) spectra. The catalyst XPS spectra showed three obvious peaks, that the bigger binding energy on the left-side was the peak of $641 \mathrm{eV}$, which was the absorption peak of manganese; the binding energy in the middle peak was $530 \mathrm{eV}$, which was the absorption peak of oxygen; peak with the biggest binding energy was $284 \mathrm{eV}$, which was the absorption peak of carbon. The surface element concentrations of Mn-Fe/CNTs catalyst sample measured by XPS were: $87.27 \%$ of C, $7.48 \%$ of O, $3.44 \%$ of Mn, $1.64 \%$ of Fe. It can be seen from Figure 3 that there was one peak respectively at the binding energy of $641.1 \mathrm{eV}$ on the $\mathrm{Mn}(2 \mathrm{p})$ spectrogram of Mn-Fe/CNTs catalyst, in addition, $641.1 \mathrm{eV}$ corresponded to $\mathrm{MnO}_{2}$, which were consistent with the report of literature [6]. There were some peaks respectively at the binding energy of $710.9 \mathrm{eV}$, this corresponded to $\mathrm{Fe}_{2} \mathrm{O}_{3}$.

\subsection{Effect of Temperature on SCR Activity of Mn/CNTs Catalyst}

Figure 4 presented the effects of impregnant solution concentration to the NO conversion rate under different reaction temperature conditions.

It can be indicated from Figure 4 that the NO conversion rate of catalyst prepared with different concentrations of impregnation increased with the rise of impregnant concentration under different reaction temperature conditions. The different concentration of impregnant solution played an important role for NO conversion in SCR with $\mathrm{NH}_{3}$. With the increase of the concentration of impregnant solution, the NO conversion of catalysts was increasing initially then 


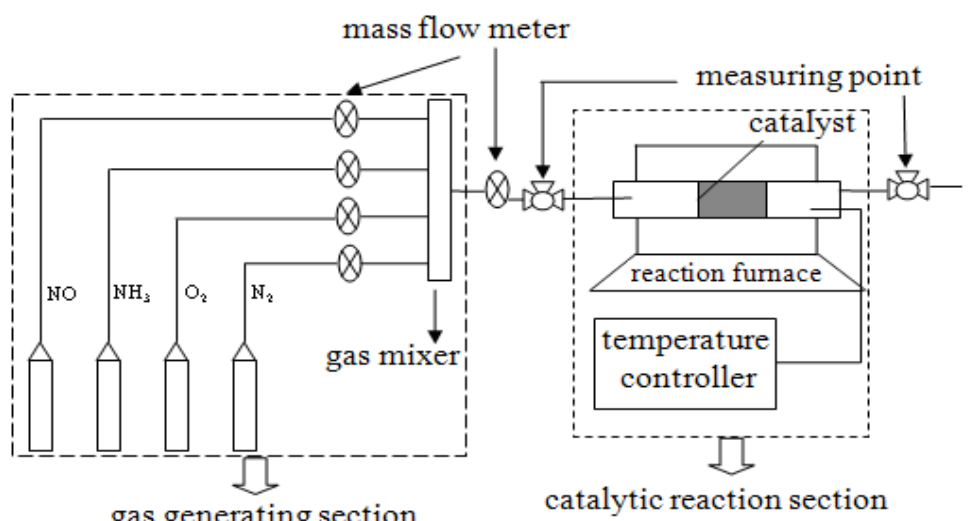

Figure 1. Experimental apparatus for activity test.

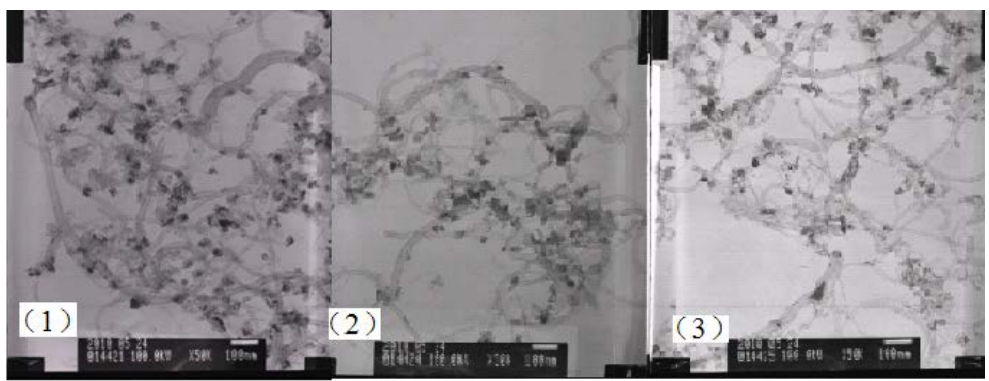

Figure 2. TEM image of samples: (1) Mn/CNTs; (2) 10\%Mn-Fe/CNTs; (3) $20 \% \mathrm{Mn}-\mathrm{Fe} / \mathrm{CNTs}$.
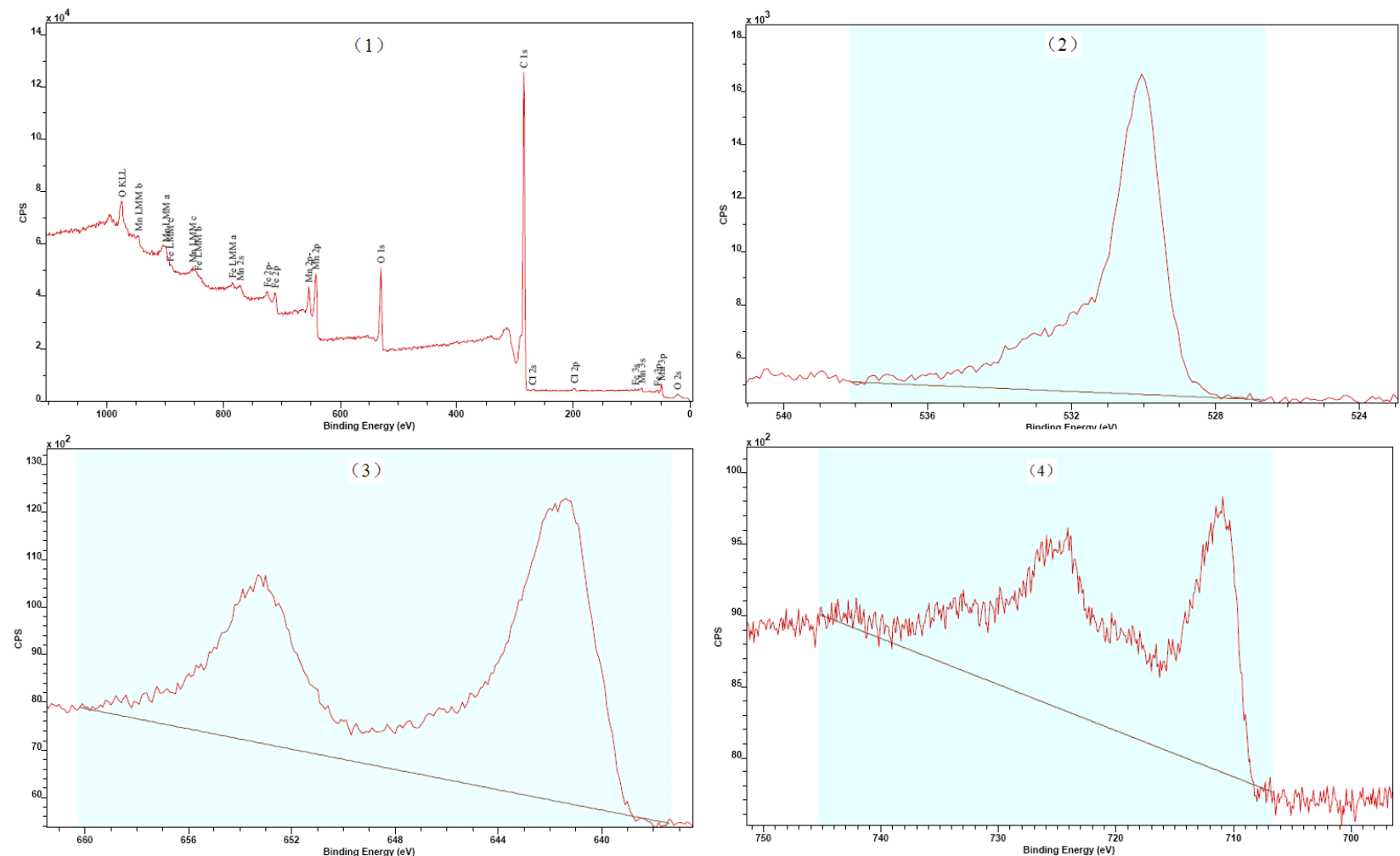

Figure 3. XPS spectra of the Mn-Fe/CNTs: (1)Mn-Fe /CNTs, (2) O(1s), (3) Mn (2p), (4) Fe(2p). 


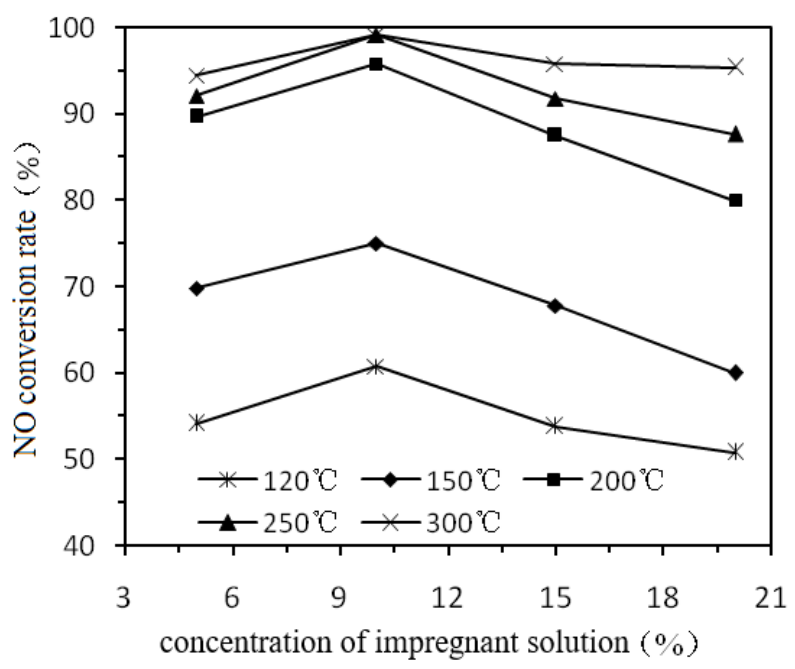

Figure 4. Effect of impregnant concentration on the activity of $\mathrm{Mn}-\mathrm{Fe} / \mathrm{CNTs}$ (Reaction conditions: $450 \mathrm{ppm} \mathrm{NO}, 500 \mathrm{ppm}$ $\mathrm{NH}_{3}, 5.0 \% \mathrm{O}_{2}$, WHSV of $\left.30,000 \mathrm{~h}^{-1}\right)$.

decreasing. The NO conversion increased with increasing of impregnant concentration in the range of ratios from $5 \%$ to $10 \%$. When the impregnant concentration continued to exceed $10 \%$, the NO conversion decreased. For the impregnant concentration $<10 \%$, the active sites provided by the catalyst surface was increased gradually. But excessive of impregnant concentration, the catalyst surface was overloaded with metal oxides, the surface area of the active substances on the catalyst surface decreased lead to the decease of the activity of the catalys.

\section{Conclusions}

The specific surface area of CNTs being the carrier of catalyst increased significantly after experiencing purification through nitration. Active components can load on the surface of CNTs with the augment of impregnation concentration of impregnating solution.

The species of active components loaded on the catalyst were $\mathrm{MnO}_{2}$ and $\mathrm{Fe}_{2} \mathrm{O}_{3}$. The different concentration of impregnant solution played an important role for $\mathrm{NO}$ conversion in SCR with $\mathrm{NH}_{3}$. With the increase of the concentration of impregnant solution, the NO conversion of catalysts was increasing initially then decreasing.

\section{Conflicts of Interest}

The author declares no conflicts of interest regarding the publication of this paper.

\section{References}

[1] Poncharal, P., Wang, Z.L., Ugarte, D. and de Heer, W.A. (1999) Electrostatic Deflections and Electromechanical Resonances of Carbon Nanotubes. Science, 283, 1513-1516. https://doi.org/10.1126/science.283.5407.1513 
[2] Dillon, A.C., Jones, K.M., Bekkedahl, T.A., Kiang, C.H., Bethune, D.S. and Heben, M.J. (1997) Storage of Hydrogen in Single-Walled Carbon Nanotubes. Nature, 386, 377-379. https://doi.org/10.1038/386377a0

[3] Ye, Y., Ahn, C., Witham, C., Fultz, B., Liu, J., Rinzler, A., Colbert, D., Smith, K. and Smalley, R. (1999) Hydrogen Adsorption and Cohesive Energy of Single-Walled Carbon Nanotube. Applied Physics Letters, 74, 2307-2309. https://doi.org/10.1063/1.123833

[4] Liu, C., Fan, Y.Y., Liu, M., Cong, H.T., Cheng, H.M. and Dresselhaus, M.S. (1999) Hydrogen Storage in Single-Walled Carbon Nanotubes at Room Temperature. Science, 286, 1127-1129. https://doi.org/10.1126/science.286.5442.1127

[5] Planeix, J.M., Coustel, N., Coq, B., Brotons, V., Kumbhar, P.S., Dutartre, R., Geneste, P., Bernier, P. and Ajayan, P.M. (1994) Application of Carbon Nanotubes as Supports in Heterogeneous Catalysis. Journal of the American Chemical Society, 116, 7935-7936. https://doi.org/10.1021/ja00096a076

[6] Coq, B., Marc Planeix, J. and Brotons, V. (1998) Fullerene-Based Materials as New Support Media in Heterogeneous Catalysis by Metals. Appl Catal A: Gen, 173, 175-183. https://doi.org/10.1016/S0926-860X(98)00177-X

[7] Zhang, Y., Zhang, H.B., Lin, G.D., Chen, P., Yuan, Y.Z. and Tsai, K.R. (1999) Preparation, Characterization and Catalytic Hydroformylation Properties of Carbon Nanotubes-Supported Rh-Phosphine Catalyst. Appl Catal A: Gen, 187, 213-224. https://doi.org/10.1016/S0926-860X(99)00229-X

[8] Liang, C., Li, Z., Qiu, J.S. and Li, C. (2002) Graphitic Nanofilaments as Novel Support of Ru-Ba Catalysts for Ammonia Synthesis. J Catal, 211, 278-282. https://doi.org/10.1016/S0021-9517(02)93724-3

[9] Zhang, H.Z., Qiu, J.S., Liang, C., Wang, X., Wang, Y.P., Feng, Z.C. and Li, C. (2005) A Novel Approach to Co/CNTs Catalyst via Chemical Vapor Deposition of Organometallic Compounds. Catal Lett, 101, 211-214. https://doi.org/10.1007/s10562-005-4893-3

[10] De Jong, K.P. and Geus, J.W. (2001) Carbon Nanofibers: Catalytic Synthesis and Applications. Catal Rev-Sci En, 42, 481-510. https://doi.org/10.1081/CR-100101954

[11] Serp, P., Corrias, M. and Kalck, P. (2003) Carbon Nanotubes and Nanofibers in Catalysis. Appl Catal A, 253, 337-358. https://doi.org/10.1016/S0926-860X(03)00549-0 